\title{
EVALUATION OF FIRM BY PRODUCTS CATEGORIZED
}

\author{
Akira Yoshinari \\ Assoc. Prof., Aichi Institute of Technology, Japan, yoshinari@aitech.ac.jp \\ Abstract
}

This research is about how companies which have products that are labeled into a product category are evaluated and are praised. Being labeled into a category means that a group of products are represented by characteristics already known to consumers, in effect being categorized.

Existing research has shown that companies which have products that can be easily labeled into a product category are judged highly by reviewers and garner more attention. These products are called prototype about the category. On the other hand, companies which do not have products that fit into a category well or not at all are given poor evaluations. Thus, this research shows that companies who have products which can be partly labeled into a product category would be evaluated as better than those which cannot.

This study will focus on "mini" insurance companies and compare the products which have already been categorized and those that have not. Furthermore, this study sets out to prove that after the more a company has products which are being labeled into product categories, the more likely that company would be able to achieve better reviews. As a result, this research will show that a company could increase high evaluations by reviewers by focusing on being labeled into a product category.

Keywords: Category in Market, Prototype, Label of Category, Innovation, "Mini" Insurance.

\section{INTRODUCTION}

Consumers generally deal with products on the market. In so doing, if a product is highly evaluated by comparison, consumers are motivated to purchase the product. If the product has a low evaluation, the consumers may hesitate in purchasing it (Zuckerman, 1999, Yoshinari, 2015).

However, there exists a stage prior to the evaluation of individual products on the market by consumers. This refers to the evaluation of what sort of attributes such products have. Before consumers evaluate individual products, they evaluate what sort of products they are, with what sort of attributes. Thereafter, within the scope of the attributes, they evaluate which product is superior.

In this way the presentations of products evaluated by consumers as having the same attributes are referred to as product category. Based on internal presentations called a category, consumers recall certain products, and through the presentation, namely this category, they evaluate the products. Thus, the market can be called an assembly of product categories. Such assembly of categories is referred to as market infrastructure (Durand et al., 2013).

There are some products in which the evaluation of category is easy, as to what sort of attributes they have, while such evaluation is difficult for other products. Products in which it is easy to determine which category they belong to are representative of that category and become typical products of that category. Products typical of a certain category are called prototype products of that category. 
This study focuses on the formation of a prototype in a category which influences the evaluation of products. We will examine how such a product prototype is formed and how such product prototype comes to be recognized by consumers.

In this study, we shall survey the Japanese insurance industry. In the Japanese insurance industry, we will examine the so-called mini-insurance category and how such a prototype came to be formed. In particular, we will discuss, not category formation through a prototype as we have considered thus far, but rather prototype formation through a category. As a result of such consideration, we shall also be able to examine how the aforementioned affects product evaluation.

Through this study, we shall endeavor to specify the causal relationship between product category and prototype, as well as to implicate the possibility of a category label changing the prototype. We shall also indicate how the above-mentioned influences the products and corporate evaluation, leading into the conclusion of this paper.

\section{PRIOR RESEARCH}

\subsection{Product Category and Prototype}

In this study, we would like to discuss product category as one means of market classification.

Such product category is studied because depending on which product category the consumers place the product in, product evaluation is directly affected, and the evaluation of the company which launches the product is indirectly affected (Negro et al., 2010).

Consumers evaluate various products according to their attributes. Some products have multiple attributes, which are often in a nested structure. For example, an insurance product has not only an attribute called insurance, but therein, an attribute called life insurance, and therein, an attribute called medical insurance, and further therein, an attribute called cancer insurance.

In this study, the product attributes which are internal presentations of consumers are called product category. As mentioned earlier, it has a nested structure, and envelops the entire market as an assembly of product category. Through this product category, consumers are able to simplify a complex market. Furthermore, through the product category, expectations for the product and faith in the company which has introduced such products into the market are able to be cultivated.

How then, are internal presentations called product category created by consumers, based on product attributes? A traditional concept of category is a strict interpretation of category. Such concept dictates that only categories with a common attribute are included in the assembly of categories. For example, birds have a characteristic of having the ability to fly. Therefore, flightless birds are not birds. Such strict interpretation of category stands on the premise that attributes can be clearly defined.

However, the boundary between categories cannot be so strict (Rosch, 1975; Rosch and Mervis, 1981). Flightless birds are also included in the bird category. In other words, if they have wings and walk on two legs, they are included in the bird category. Strictly speaking, since flightless birds are also included, such assembly which is formed is called family resemblance. Similarly, product category is formed not through strict attributes, but through family resemblance.

According to family resemblance, what is important is not what an attribute for a particular category is, but rather the object representing that category. Whether that object is included in a certain category is dependent on how similar other objects are In relation to that object.

A typical object within a category representing that category is called a prototype. Through similarities with the prototype, it can be determined whether an object can be included in that category. Therefore, since the evaluation criterion is merely how similar a particular object is to the prototype, it is not clear where the boundary of that category is.

Thus, the existence of a prototype is vital in the formation of a category. The reason is, in order to form and maintain a category, the vital aspect is the recognition of how close a product is to the prototype. Even if the product does not have a particular attribute, the boundary between the categories is obscured due to family resemblance, since the product can belong to that category.

\subsection{Characteristics of a Prototype}

The product which is the prototype of a certain category prompts the consumers to call to their minds the category as well as the prototype product. In other words, in comparison to a non-prototype product, a 
prototype product becomes a relatively familiar existence to the consumers. Consequently, this influences the evaluation of the product.

When taking a glance at a prototype product, one can understand what characteristics that category has. Thus, becoming a prototype product involves clearly having the product characteristics. By extension, if a product is a prototype, it leads to faith on the part of the consumers that the expected results may be attained.

However, within a category, there are products which extremely resemble the prototype, whereas some products only partially resemble the prototype. If a product resembles the prototype, the consumers will develop faith that the expected results will be attained, whereas if a product does not resemble the prototype, the consumers may have doubts regarding the possibility that the expected results may not be attained.

Zuckermann (1999) stated that the distance from the prototype, namely the difference between the product similar to the prototype and the product not similar thereto, results in the difference in the evaluation by the consumers. In other words, there is a difference in evaluation between prototype products and non-prototype products. Consumers highly evaluate prototype products and products resembling the prototype. By contrast, consumers have a low evaluation toward products not resembling the prototype.

\subsection{Formation of a Prototype}

How then, is a prototype formed? The formation of a prototype may be divided into 2 models. For example, imagine how one product may be innovative in an unprecedented way, and is widely accepted by consumers. As a result, other companies introduce into the market products similar to the aforementioned product. In such a situation, the consumers try to bulk together into one group, not only the initial innovative product, but other similar products as well. In so doing, the consumers regard the initial innovative product as a prototype and form a product category.

However, according to this model, if an innovative product fails to exist, neither the prototype nor the category is formed. The other model is based on a concept that in an inter-category comparison, a category is formed, along with a prototype. In this instance, a prototype product may not necessarily be an innovative product. In short, an existing product may become a prototype in a category. In contrast to the prototype formation pattern in the previous model which is limited only to innovative products, this latter model which includes the formation of a prototype with an existing product, is more realistic.

Since the latter model does not involve new products, the product label itself becomes vital. When a specific label is affiliated with an existing product creating a new relationship, the existing product becomes a prototype. That is, the formation of a prototype in a certain category is related to whether or not a relationship with a category label and a prototype product is created.

\section{RESEARCH METHODOLOGY}

The aim of this study is to develop a hypothesis by means of quantitative research based on article search and qualitative research based on interview surveys and semi-structural questionnaires.

The qualitative aspect of this study is based on interview surveys. The subjects of the interview surveys were 3 mini insurance companies. The term of the survey was from August, 2015 to September, 2015. The semistructural questionnaires regarding mini insurance labels were given to the public relations department of mini insurance companies.

The quantitative aspect of this study is based on "Nikkei" newspaper article search. In order to gauge the communication of the category audience in the market, a chronological record is made of the number of keyword hits that a category label receives based on the article search database of various newspapers. Newspapers are, in effect, an audience who serve as a critic communicating with the category producer, and an intermediary enabling the category to be widely accepted by society. Therefore, this indicates that the more hits a label receives, the more frequent the communication between the newspaper, as an audience, and the category producer. By extension, it means that the category producer is communicating on a wide scale to society, as an audience, by means of the newspaper.

\section{RESULT}

\subsection{The Qualitative Aspect of This Study}

The purpose of this study is to establish the change in a category label and how a prototype is formed. As a result thereof, we will compare consumer evaluation between prototype products and non-prototype products. 
It was around 2003 that mini insurance as a product category appeared in the Japanese domestic market. Although there have been similar products on the market previously, the name "mini insurance" did not exist, and the product was introduced into the market under the name "unauthorized cooperate insurance."

However, this term "unauthorized" meant that despite operating an insurance business, there was no applicable law such as the Insurance Business Act. Thus, it became a social issue that such a company was in operation. For example, one unauthorized cooperate insurance company, while selling medical insurance and corporate bonds, were collecting money from union members and soon after ended up in dissolution.

Amid such a climate, the Insurance Business Act was revised in 2006, and the unauthorized cooperate insurance companies were urged to choose between becoming an insurance company on a license system with a minimum capital of 1 billion yen, or to become a small amount and short-term insurance provider on a registration system with a capital of 10 million yen. While becoming a small amount and short-term insurance provider was relatively easier option to the former, such unauthorized cooperate insurance companies could not even become a small amount and short-term insurance provider and ended up discontinuing their operations.

Nevertheless, from 2006 onward, while many unauthorized cooperate insurance companies gradually wound up their companies, small amount and short-term insurance companies became commonly known as mini insurance, and an increase was seen in companies newly entering the market. Among the new market entrants were funeral directors and IT companies. There was also an increase in other types of companies which began to participate in the insurance business.

In particular, there were many companies which entered the pet insurance, home contents insurance and medical insurance market. Pet insurance existed only in the highest growth small amount and short-term insurance. In contrast, home contents insurance in preparation for earthquakes and medical insurance in preparation for hospitalization were, on one hand, sold as part of damage insurance up to that time. On the other hand, medical insurance was also sold as part of a life insurance product.

Specifically, the existence of the category of home contents insurance and medical insurance, which are products falling under the category of mini insurance, once again came into the spotlight. Under normal damage insurance, the premiums as well as the payments are high. However, in the home contents insurance under mini insurance, the premiums as well as the payments are low. Therefore, it caters to the consumer needs of being able to join the policy without reserve and prepare for potential risks. From such perspective, products which aptly fit the description of mini insurance began being launched into the market.

As a result, even to this day, many companies are entering this industry. Some damage insurance companies have established mini insurance companies as their subsidiaries. In other cases, companies from other industries have bought out existing mini insurance companies. In such manner, competition is intensifying.

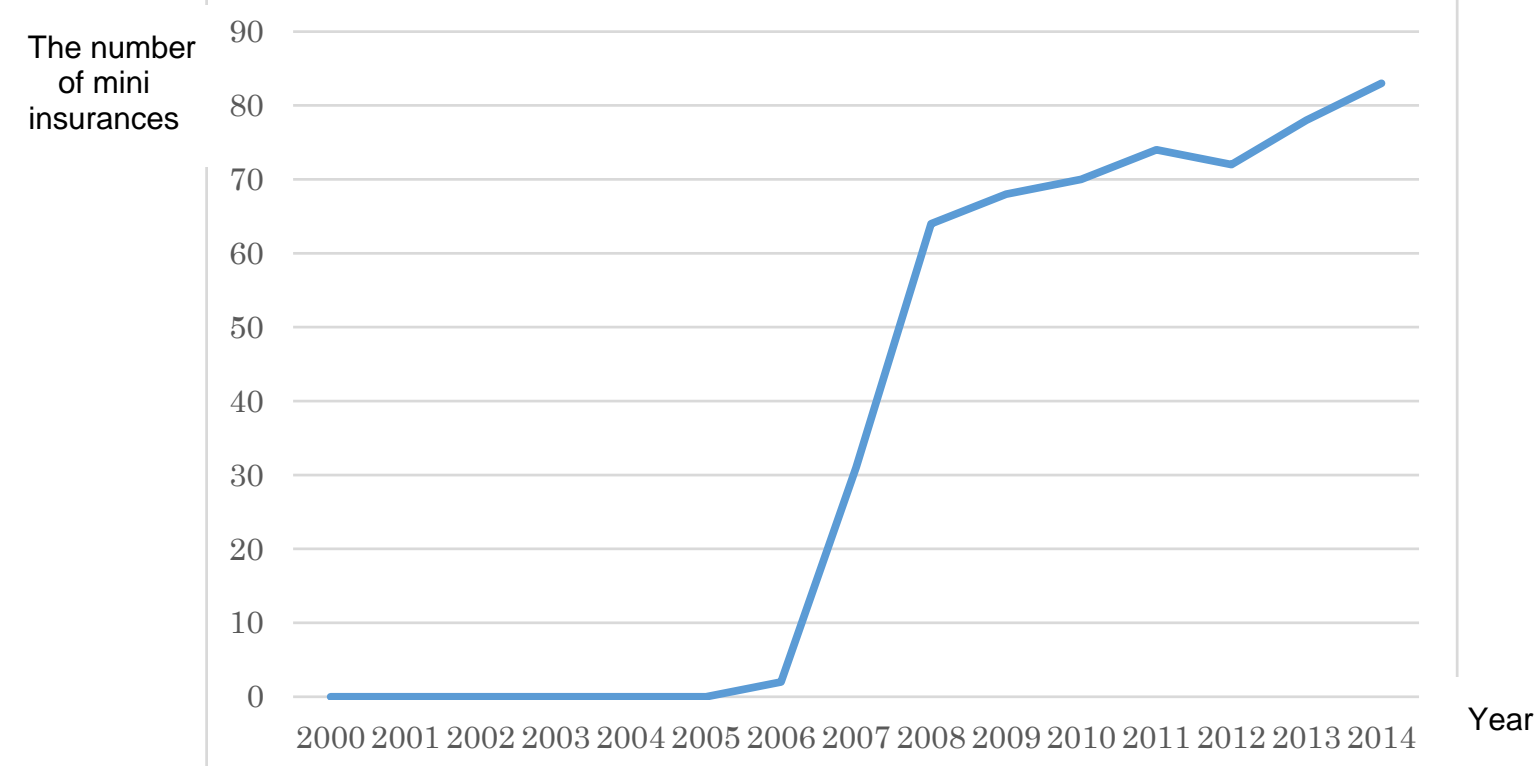

Fig. 1. The number of mini insurances 


\subsection{The Quantitative Aspect of This Study}

Figures 2 to 4 indicate the results of text mining. The key word "unauthorized cooperative insurance" was extracted in chronological order from fiscal year 2002 (from April, 2002 April 2003) to 2014 from newspapers. Nikkei newspaper was used as the text.

Figure 2 shows the results of "unauthorized cooperative insurance." With the years 2004 and 2007 as the peak, the keyword gradually declined. Although there was a slight temporary increase in the year 2010, the increase was due to articles dealing with revisions in the legal system regarding unauthorized cooperative insurance.

The number of

mini keywords

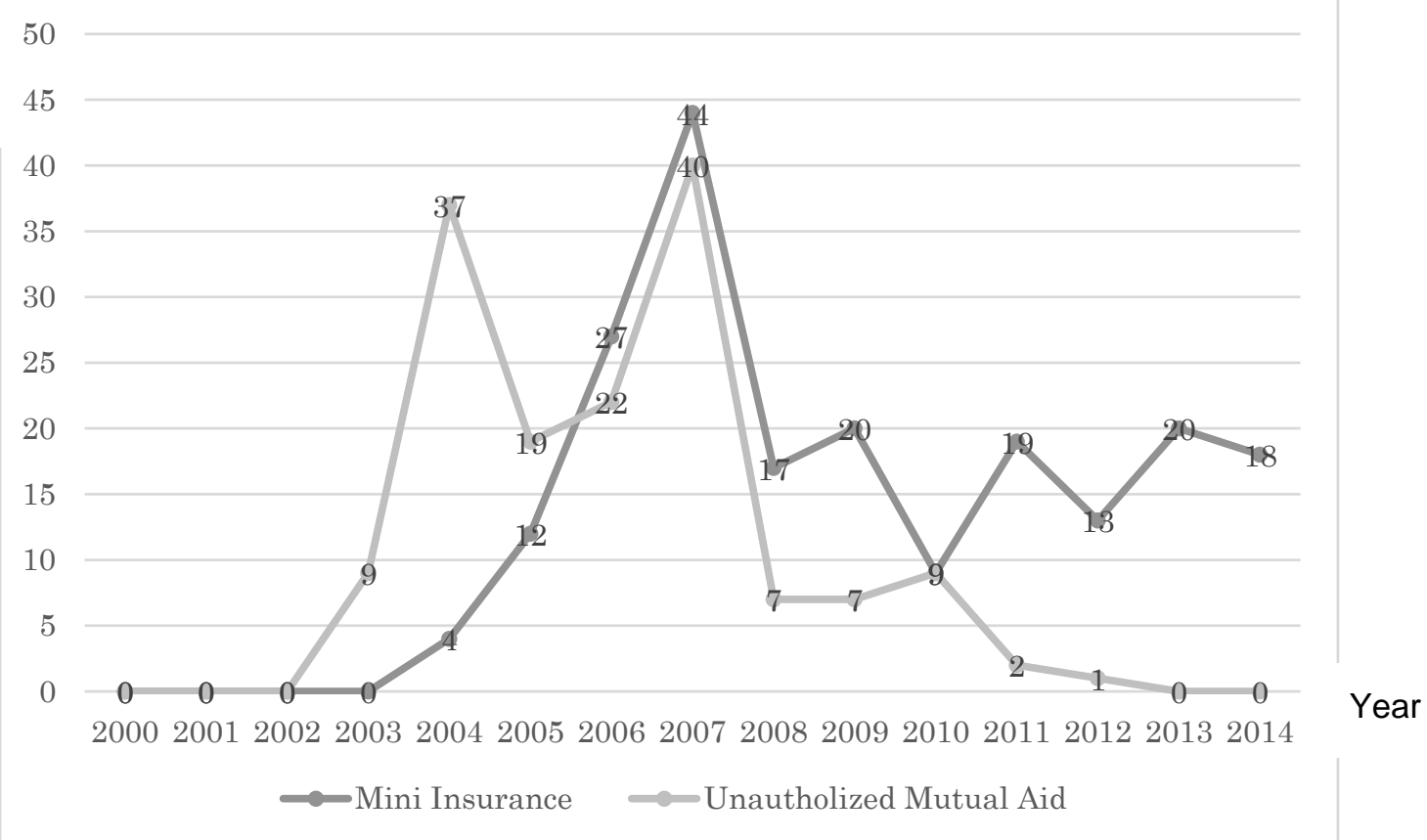

Fig. 2. The terms of mini insurance and unauthorized aid in text mining

Figure 3 indicates results for the keyword "small amount and short-term insurance", and Figure 4 indicates the results for "mini insurance." Both Figures 3 and 4 show that with the 2007 as the peak, the year after the law revision, there is a temporary decline; however, a gradual increase is seen thereafter. Specifically, the keyword "mini insurance" is seen to have increased even more so than the keyword "small amount and short-term insurance." In other words, it is perceived that the keyword "mini insurance" has become a more familiar term compared to "small amount and short-term insurance." Furthermore, when comparing the keyword "mini insurance" in Figure 4 and the number of mini insurance businesses in Figure 1, the number of mini insurance businesses has increased side by side along with mini insurance. Mini insurance and the number of mini insurance businesses are seen to be correlated. 


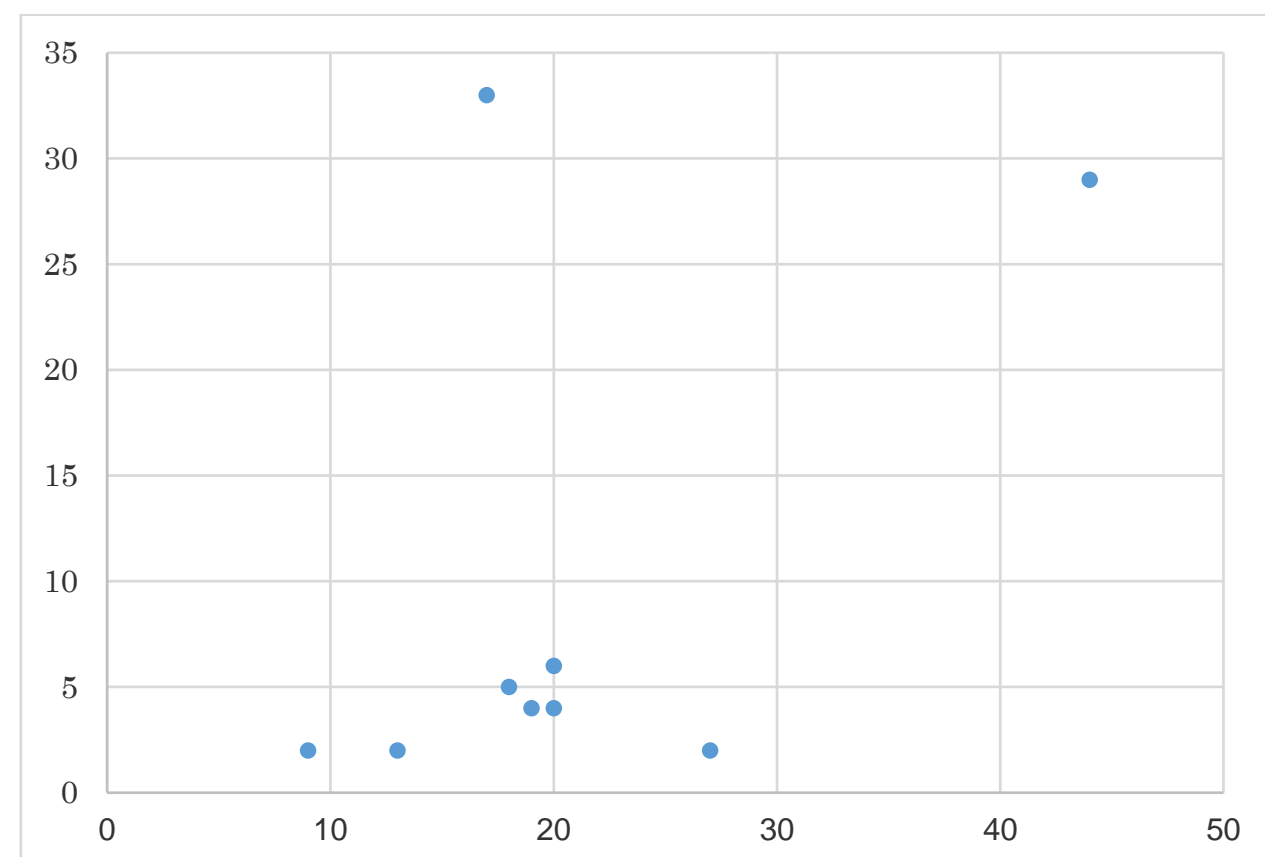

Fig. 3. Correlation between the term mini insurance and increase of mini insurance $r=0.50$

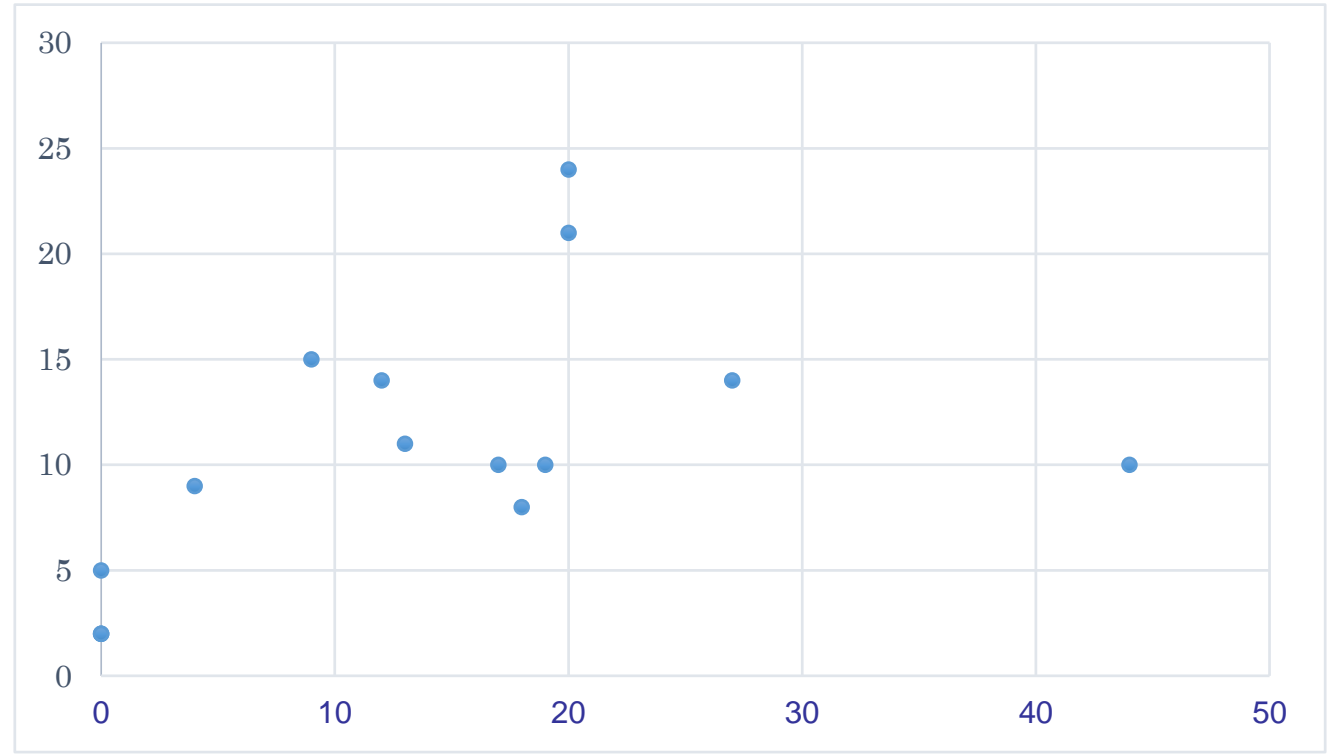

Fig. 4. Correlation between Mini insurance and Pet insurance

$$
r=0.52
$$

\section{DISCUSSION}

Based on the foregoing results, category and prototype, as well as company evaluation shall be considered. First of all, the products which are the subject of this survey are not innovative commodities. Rather, these are commodities which have been in existence since before the year 2000. Nonetheless, the number of such products has been on the increase, and the businesses handling these commodities have also been gradually increasing. In short, a new market has been created, not due to factors related to the commodities themselves, but due to some other factors.

One highly probable factor is the category label called mini insurance. By giving a name to a label, which is a new category in the market, the awareness of mini insurance on the part of consumers has been enhanced, resulting in the heightening of product evaluation. Consequently, many companies entered that market. 
Of particular note are the characteristics of the label, which is mini insurance and not small amount and shortterm insurance. The term "mini insurance" which has the connotation of being small in size in comparison to normal insurance, although not having much impact on pet insurance, had a profound impact on home contents insurance and medical insurance. As an example, such impact stems from launching a commodity called mini insurance into the market, while being clearly aware of medical insurance under life insurance. In particular, in comparing the premiums of medical insurance under life insurance with those of mini insurance, there is a clear differentiation between the two. The consumers favor this fact and highly evaluate the product and the company. As a result, this market becomes appealing.

\section{CONCLUSION}

In this study, we have considered the formation of a product prototype called mini insurance. For example, while both handling medical insurance, there is a clear differentiation between insurance companies and mini insurance companies. As a result, the commodity of the mini insurance company forms a category prototype called mini insurance.

From the foregoing, as far as the example of mini insurance is concerned, there is a correlation between product category and prototype. As the product category label is changed and a new market is gradually formed, a prototype which matches the label's image becomes a commodity. In other words, it has been verified that a prototype is formed by category.

In this paper, company evaluation with regard to category has been considered. It is difficult for consumers to directly evaluate the company products themselves. They always evaluate products and companies based on some sort of category. This paper discussed receptivity in such evaluation, such as how a prototype is formed and through what sort of category label.

As it becomes easier for consumers to recall a category label, the consumers feel attracted the product and the company. Companies, in turn, launch products into the market which consumers find appealing. As a result, the product becomes a category prototype. A prototype product is highly evaluated by consumers, and similarly highly evaluated by companies. Thus, other companies introduce products similar to the prototype into the market, resulting in the vitalization of the market.

The implication of this study is not the logic presented thus far that a prototype is formed and a category is formed thereafter. Rather the new logic which has been derived is that a prototype is formed through a category, using the example of insurance. In the future, we intend to closely investigate this matter further.

\section{REFERENCE LIST}

Durand, Rodolphe \& Lionel Paolella. (2013). "Category Stretching: Reorienting Research on Categories in Strategy, Entrepreneurship, and Organization Theory." Journal of Management Studies. Vol. 50, Issue 6, pp.1100-1123.

Giacomo Negro, Ozgecan Kocak, Greta Hsu. (2010). "Research on Categories in the Sociology of Organizations. Introduction to Volume on Categories in Markets: Origins and Evolution." Research in the Sociology of Organizations. Vo.31, pp.3-35.

Rosch, E. H. (1975). "Cognitive Representation of Semantic Categories." Journal of Experimental Psychology. Vol.104, No 3, pp.192-233.

Rosch, E.H.and Mervis, C.B. (1981). "Categorization of Natural Objects." Annual Review of Psychology. Vol.32, pp.89-113.

Zuckerman, E. 1999. "The Categorical Imperative: Securities Analysts and the Illegitimacy Discount." American Journal of Sociology. Vol.104, pp.1398-1438.

Yoshinari,A. (2015). "Rebuilding of Collective Categories with Revolutionary Category: A Case of Generics in Japanese Medical Pharmaceutical Industry." Journal of Japanese Information Management. Vol.34, No.3, pp.44-57. (In Japanese)

Nikkei Newspaper 